\title{
The Game Between National Propositions and Provincial Propositions from the Perspective of Fairness
}

\author{
Xie Dongping ${ }^{1,2}$ \\ ${ }^{1}$ Institute of Educational Sciences, Huazhong University of Science and Technology, Wuhan, China \\ ${ }^{2}$ Department of Teacher Education, Honghe University, Mengzi, China
}

Email address:

835975537@qq.com

To cite this article:

Xie Dongping. The Game Between National Propositions and Provincial Propositions from the Perspective of Fairness. Education Journal. Vol. 8, No. 6, 2019, pp. 286-295. doi: 10.11648/j.edu.20190806.18

Received: November 25, 2018; Accepted: January 2, 2019; Published: November 13, 2019

\begin{abstract}
The college entrance examination proposition management system is facing a new round of reorganization and adjustment. The switch between national proposition and provincial proposition reflects the game between national interests and local interests, and becomes a beneficial attempt and exploration to resolve the risk of college entrance examination. However, before the differences in enrollment quota allocation patterns have not been eliminated, the point of equality between national propositions and provincial propositions is not in the propositional system itself. The proposition of the college entrance examination directly affects the allocation, development and cultivation of basic education resources and further influences the development potential of regional basic education and ultimately the fairness of basic education. Therefore, the fairness of basic education is a subject that can not be circumvented by national propositions and provincial propositions. Under the current trend of returning to the national proposition, to achieve a quality education equity, it is committed to give more freedom for university entrance Exam and strengthen the professionalization of local examination institutions and enhance the level and ability of local examination institutes, At the same time, the government should consider the reality of local basic education and improve the level of local basic education.
\end{abstract}

Keywords: Fairness, National Proposition, Provincial Proposition, Basic Education

\section{Introduction}

The college entrance examination in our country not only plays an important, profound and strong role in guiding and stimulating the basic education teaching [1], but also has a high social relevance. It has already surpassed the superficial significance as a means of selecting talents in Colleges and universities. It is not only related to the way everyone chooses his career and future life [2], but also exists as a breakthrough and witness reflecting the changing social situation. Since the establishment of the college entrance examination in 1952, "Due to the restriction of tradition and reality, the college entrance examination of the Chinese people has become culture, politics, economy, grand ceremony, social activity concerned by all sides, and general mobilization of the whole people" [3]. Because of the great social and educational influence of the college entrance examination and the close connection with the interests of many parties, fairness has become the pronoun of the spirit of the college entrance examination, and it is regarded as the soul and foundation of the college entrance examination system [4]. Therefore, the concept of fairness not only runs through the reform, but also is the key basis for judging the success or failure and effectiveness of its reform measures in the reform of college entrance examination. As the carrier of realizing the function of college entrance examination and fulfilling the function of talent selection, the proposition system of college entrance examination can most intuitively reflect the concept of fair value of college entrance examination, which has become a very deep and wide-ranging part of the reform of college entrance examination.

The proposition is fundamental to the examination and is also crucial to the fairness of examinations. [5] Since the founding of the National College Entrance Examination System in China, in the past reform of the College Entrance Examination, the government and relevant education authorities have actively tried to reform the proposition of the College Entrance Examination. These reforms involve not 
only the content of propositions: the design of subject types, the value orientation of examination papers, etc., but also the technical level of propositions: the construction of question bank, the standardization of proposition process, the application of information technology, etc.. There are also aspects of proposition organization form: autonomous proposition of universities and so on. These problems are embodied and reflected in the game between the national propositionand the provincial proposition. The proposition of "national proposition" or "provincial proposition" has been long-standing and controversial. On the surface, it reflects the change of proposition ownership, however, in essence, it is a systematic reform of proposition management system of college entrance examination. National proposition and provincial proposition, from a macro perspective, are related to the relationship between government, society and education system at all levels and their operation forms; from a micro perspective, they include the organizational division of labor, propositional authority and the relationship between interest groups, and then affect the change of propositional content at a more subtle level. And reform. Therefore, it is of global and holistic significance to discuss the fairness of National proposition and provincial proposition. With the scale of higher education approaching the stage of popularization, the deepening of the comprehensive reform of education, the further expansion of the autonomy of universities and the deepening of the new curriculum reform of basic education, the reform of the college entrance examination system in China has entered a new historical turning point, and the management system of college entrance examination proposition is also facing a new round. Adjustment of unification and division. Faced with these changes, the research need to further explore whether there will be new changes in the connotation and meaning of the fairness of the college entrance examination, what impact will be exerted on the college entrance examination system and basic education, and what kind of college entrance examination proposition system is a good proposition system.

\section{Reform of College Entrance Examination Proposition Management System that Tends to Complement and Integrate}

"The history of an examination is the history of repeated and repeated disputes."[6]Since the establishment of the College Entrance Examination System in 1952, the ownership of propositions in the National College Entrance Examination has been wavering between unified propositions and provincial propositions. In 1952, under the background of highly centralized planned economy system and omnipotent government management mode, the proposition of national unity was implemented. Until 1958, the provincial proposition was tried out for only one year and returned to the unified proposition of the whole country; the Cultural Revolution College Entrance Examination was interrupted, and the system of College Entrance Examination was rebuilt in 1977. Because of the hasty preparation, the provincial and branch schools adopted the separate proposition; Since 1978, the national unified proposition was implemented again; In 1985, the provincial proposition was regarded as the strategic need to comprehensively promote quality education. And began to pilot in Shanghai with the reform of the college entrance examination system."Basic education in China is the responsibility of each province separately. Each province has direct and main responsibility for the improvement of basic education in this province. If every province can participate in the proposition of college entrance examination, it will be of great benefit to the reform and development of quality education in primary and secondary schools in this province." [7] In 2002, Beijing also launched its own propositions. The theft of college entrance examination papers in June 2003 [8] became a direct fuse for further expansion of the provincial proposition. In 2004, the Ministry of Education increased the scope of provincial propositions to 11 provinces and cities. In 2006, the number of provinces, municipalities and autonomous regions with autonomous propositions increased to 16, with the exception of Hong Kong, Macao and Taiwan, and the province that divides the province proposition covers Eastern, central and western regions. This pattern lasted until 2014. In September 2014, the State Council promulgated the "Opinions on the Implementation of Deepening the Reform of Examination Enrollment System", which clearly pointed out that:"Increasing the number of provinces using the national unified examination paper since 2015" [9]. In 2015, 3 provinces were added to the national volume, while 7 provinces were added in 2016. By 2017, 25 provinces and municipalities have used different versions of national papers, and the way of proposition has changed into "1 (national papers made by the examination center of the Ministry of Education) +5 (provincial propositions of Shanghai, Beijing, Tianjin, Zhejiang and Jiangsu)".

Throughout the changes in the ownership of college entrance examination propositions since 1949, there has been a gradual trend towards complementarity and integration in the alternation of national propositions and provincial propositions [10]: Firstly, since the 1990s, except for individual years, the mode of proposition for college entrance examination in China has not only adopted one mode, but also combined the national unified proposition with the provincial proposition. Second, even in provinces where the province is divided into provinces, some of the subjects still use the national volume. For example, almost all provinces have been tested by the Ministry of education examination center. In 2011, only language, mathematics (divided into liberal arts, science) and English are autonomous propositions in Hubei and Hunan provinces, while liberal arts (politics, history, geography) and science (physics, chemistry and biology) are unified by the examination center of the Ministry of Education. Thirdly, different versions of papers under the same proposition center: In recent years, in the provinces using national papers, the examination center of the Ministry of Education has made different versions of national papers 
according to the different needs, education and regional differences of the provinces, such as the new curriculum standard one volume, the new curriculum standard two volumes, etc., for different provinces to use.

\section{Focus on the Debate and Game of Fair National Proposition and Sub Provincial Proposition}

The changes of national propositions and provincial propositions are relatively frequent compared with the reform of the whole framework of the college entrance examination system. The overall thinking of the reform is not entirely consistent with that of the pursuit of stability in the idea of college entrance examination reform. In the reform of college entrance examination proposition system, whether national proposition or provincial proposition, they always face the situation that they think they are reasonable. To study these disputes carefully, the arguments of all parties are based on fairness, that is, what kind of proposition system is the fairer proposition system, or what kind of proposition system is the more reasonable and better proposition system?

\subsection{Fairness Is the Focus of Controversy in National Proposition and Sub Provincial Proposition}

Examination connotes the principle of "survival of the fittest" to encourage competition, the examination subjects in a certain organization are based on the purpose and needs of examinations. It is a kind of social activity that examiners in certain organizations select and use relevant resources to measure, screen and evaluate the quality and level of examinees in certain aspects according to the purpose and needs of examinations [11]. Therefore, fairness has become the core spirit and value support of examinations. The fairness of examination requirements should not only embody procedural fairness, but also be a kind of institutional fairness that requires attention to result justice [12]. College Entrance Examination, as the most important and highly beneficial examination system, shoulders not only great educational responsibilities: comprehensively evaluating the education received by students at the stage of basic education, then distinguishing individual differences and diverting them accordingly, but also social functions such as allocating educational resources and maintaining stability. Some scholars have said that: "Throughout the evolution of the College Entrance Examination, there are not only educational factors, but also complex social dynamic factors. It is closely related to the changes of social and political situation, and often becomes an important part of the political movement, and even a 'breakthrough' of social change" [13]. Because of this, in the reform of college entrance examination, concepts such as efficiency have all given way to the idea of fairness, which has become an integral part of the reform of college entrance examination. It is considered that only the reform of college entrance examination which fully demonstrates fairness is the "only way" [14] for its healthy development.
Looking at the reform measures of college entrance examination since 1949, such as the change of examination time, the online admission based on technological progress, etc., which are beneficial to the interests of candidates and embody the principle of educational justice, it is easier to get the general approval of the people. However, the reforms that violate the rights and interests of candidates, such as student escort system and independent proposition, are often controversial, which leads to the twists and turns of the reform of college entrance examination. It can be said that any reform in the college entrance examination system is based on fairness as its main value orientation. In the game between national proposition and provincial proposition, fairness is not only the main value concept supporting its reform, but also the primary value concept of its reform. Fairness is not only the ultimate spiritual pursuit of the reform of college entrance examination proposition management system, but also the most critical reason and tool for the switch between national proposition and provincial proposition: Compared with the provincial proposition, the national proposition confronts the principle of equality of all people before scores and guarantees the fair access to educational opportunities and rights. It testifies and represents the basic logic of social justice: equality of opportunity, free participation and deserving. Compared with the national proposition, the provincial proposition pays attention to the difference and protects the "bottom line justice" in the backward areas [15]. Therefore, whether national or provincial propositions, fairness is always the key issue that can not be avoided in the game process. Looking at the relevant literature and the practice of the reform of college entrance examination proposition management system, both national proposition and provincial proposition have their own reasons to prove that they are fairer. Fairness has become a powerful weapon to challenge and attack each other. From this point of view, the switch between national propositions and provincial propositions seems to be a necessary and expedient measure on the surface. The reform only aimed at alleviating the current contradiction has been carried out. From the point of view of the sub-college entrance examination propositions, there has been an alternation between national propositions and provincial propositions, and there is no obvious rule to follow, which seems to confirm this more. In fact, although in recent years, there has been a trend of integration and complementarity between national propositions and provincial propositions, it seems more like a way to enrich the connotation of fairness. At present, the voice and action of returning the proposition of the National College Entrance Examination to the whole country are increasing day by day. The reform of the proposition management system of the National College Entrance Examination is facing a new round of adjustment and reform. National proposition? A provincial proposition? Or is it the integration of national proposition and sub provincial proposition? How to integrate? And the degree of integration? To solve these problems, the research must first clarify what kind of fairness the national proposition and the provincial proposition are concerned about, and where the fairness foothold and direction are. Only 
by straightening out these problems, The trend of reform of college entrance examination proposition management system can be viewed rationally

\subsection{The Choice of the Proposition of the College Entrance Examination Reflects the Game Between National Interests and Local Interests}

The division of national propositions and provincial propositions is not only a change in the organizational form of propositions, but also a major reform with high social relevance. Therefore, before and after each reform, major media have opened columns and invited relevant experts, front-line teachers and ordinary people to deepen the issue. Into the discussion, Guangming Daily, China Education Daily and other major newspapers and magazines actively gathered views, analyzed its advantages and disadvantages, trying to find out which way is better in the national and provincial propositions (see Table 1 for details). Take China Education Daily as an example, in 2003, after the implementation of the provincial proposition, the newspaper launched columns and articles such as "One Outline Leads, Hundreds Flowers Strive for Beauty" [16] (2005), and "Provincial Propositions, Achieving Leap-forward Development in College Entrance Examination Reform" [17] (2006). In the articles and columns, the advantages of unified examination and provincial proposition policy are listed. Around 2013, under the guidance of national policy and the questioning of provincial propositions by the society, the newspaper published a series of articles such as "Proposing to restore the unified proposition of national college entrance examination"[18], and triggered a big discussion on the advantages and disadvantages of national proposition and provincial proposition.

Table 1. Controversy on national proposition and sub provincial proposition.

\begin{tabular}{|c|c|c|}
\hline \multirow[t]{2}{*}{ National proposition } & Support & $\begin{array}{l}\text { 1. It is conducive to the fairness and scientificity of the college entrance examination, and to ensure the } \\
\text { stability of the quality and level of the test questions and so on; } 2 \text {. It can focus on the advantages of } \\
\text { educational resources and promote the balanced distribution of educational resources throughout the } \\
\text { country; } 3 \text {. It is effective and scientific in monitoring the current situation and level of basic education in } \\
\text { China; } 4 \text {. It is conducive to carrying out the spirit of new curriculum reform. }\end{array}$ \\
\hline & Question & $\begin{array}{l}\text { Regional differences are ignored; The unbalanced development of education has caused the imbalance of } \\
\text { educational development; The development of basic education can not be balanced and so on. }\end{array}$ \\
\hline \multirow[t]{2}{*}{ Provincial propositions } & Support & $\begin{array}{l}\text { 1. It pays attention to local differences, is more fair, conforms to the actual development of the province and } \\
\text { the actual level of education, teaching practice, highlights local characteristics, reduce the regional factors } \\
\text { brought about by the test bias; } 2 \text {. It matches the recruiting system according to the provincial quota; } 3 \text {. It is } \\
\text { conducive to the development of basic education, the implementation of the spirit of the new curriculum } \\
\text { reform, and reducing the psychological pressure of examinees; } 4 \text {. It is conducive to the overall management } \\
\text { of basic education by local governments, mutual learning and promotion among provinces, and joint } \\
\text { improvement of the quality and level of propositions. }\end{array}$ \\
\hline & Question & $\begin{array}{l}\text { The cost of proposition increases, social resources are wasted, the risk of proposition increases, and the } \\
\text { safety of college entrance examination is questioned; The aggravation of "college entrance examination } \\
\text { immigrants" and "off-site college entrance examination" is against social equity; The quality and level of } \\
\text { each province's proposition affect the authority of the college entrance examination and so on. }\end{array}$ \\
\hline
\end{tabular}

In essence, whether national or provincial propositions, in practice, there is no fundamental change in the rights and ownership rights of various interest groups (see Table 2 for details). As far as the policy process is concerned, neither the national proposition nor the provincial proposition has changed the current situation of overall management by the Ministry of Education. From the perspective of politics, public policy is the authoritative distribution of value to a society [19]. Even for provincial proposition work, the examination center of the Ministry of Education is still responsible for the guidance, professional training, supervision and evaluation of provincial, autonomous regions and municipalities directly under the Central Government. Provinces applying for provincial propositions must implement the National Unified Examination Syllabus for Admission to Universities and Colleges promulgated by the Examination Center of the Ministry of Education in a unified manner, and They can not change the policies of the Ministry of education such as enrollment policy, enrollment examination schedule and so on. Therefore, in the reform of college entrance examination proposition system in China, the central government departments directly determine the decentralization and centralization of proposition forms. This power of the central government effectively avoids the short-sighted behavior of limited rational people in policy formulation and implementation, and can cope with all kinds of sudden changes. It effectively maintains the authority and security of college entrance examination propositions. It pursues fairness at a relatively higher level, based on the evolution of propositions to achieve social fairness and justice. The local government has limited power, and its action strategy and focus are how to actively safeguard the local interests of the province through proposition, paying more attention to the principle of compensation and difference in fairness. John Rolls believes that the principle of difference is the best complement to the principle of efficiency."It can be seen that the principle of difference emphasizes the considerations put forward by the compensation principle. In order to treat all people equally and provide genuine equal opportunities, society must pay more attention to those who are less gifted and of less favourable social status. The idea is to compensate for the tilt caused by casual factors in the direction of equality" [20].

It can be said that in the game between national propositions 
and provincial propositions, the emphasis is only on different aspects of fairness, and there is no strict sense of "who is fairer". The switch between national proposition and provincial proposition has become a useful attempt to resolve the risk of college entrance examination. With the implementation of basic education curriculum reform in various provinces, it seems that both national proposition and provincial proposition have gained more legitimate reasons.
As some scholars have commented on the research of autonomous proposition, "autonomous proposition is not only the inevitable requirement of the diversification reform in the era of higher education popularization and the new curriculum reform of basic education, but also the realistic choice of adapting to the reality of the country and resolving the risk of college entrance examination" [21].

Table 2. Interest demands of various stakeholders in national propositions and sub provincial propositions.

\begin{tabular}{|c|c|c|c|}
\hline Subject of behavior & Right & Power & Interest demand \\
\hline $\begin{array}{l}\text { Central government } \\
\text { departments }\end{array}$ & Direct decision & $\begin{array}{l}\text { Policy-making power, administrative } \\
\text { authority }\end{array}$ & $\begin{array}{l}\text { Selecting talents and maintaining social } \\
\text { stability }\end{array}$ \\
\hline $\begin{array}{l}\text { Local government } \\
\text { departments }\end{array}$ & Policy implementation & $\begin{array}{l}\text { Policy-making power, administrative } \\
\text { authority }\end{array}$ & $\begin{array}{l}\text { Conforming to the local economic and } \\
\text { educational situation and reducing risks }\end{array}$ \\
\hline $\begin{array}{l}\text { Institutions of higher } \\
\text { learning }\end{array}$ & Implementation, support / challenge & Social elites, etc. & $\begin{array}{l}\text { Recruiting ideal students and expanding } \\
\text { university autonomy }\end{array}$ \\
\hline $\begin{array}{l}\text { Basic education } \\
\text { institutions }\end{array}$ & Implementation, support / challenge & Public opinion & $\begin{array}{l}\text { Consistent with their actual stability of } \\
\text { the propositional form }\end{array}$ \\
\hline Ordinary people, etc. & Implementation, support / challenge & Public opinion & "Learn best" and maximize self interest \\
\hline
\end{tabular}

Judging from these controversies and the practice of the reform of the college entrance examination system, fairness is always the basis: China's college entrance examination is known as the national unified entrance examination for colleges and universities. In the college entrance examination proposition system, the national proposition highlights the efficiency, comparability and authority based on fairness. Therefore, supporters of the national proposition accuse the provincial proposition of overemphasizing differences, which is just a cover-up of regional discrimination, making regional discrimination institutionalized, legalized and blurred. Provincial proposition, as a major institutional reform involving the overall situation of college entrance examination and even education, emphasizes the differences among provinces in economy, culture and education. Provincial proposition not only embodies the principle of fair compensation [22], makes up for the inequality of the starting point of competition, but also reflects the awareness and mechanism of risk-sharing responsibility of local governments in college entrance examination. Therefore, it is only a form of equity, rather than substantive fairness, to question the fairness of the national proposition. Whether national proposition or provincial proposition, there seems to be a fair reason to support, but also can be used as a weapon to denounce each other. This phenomenon shows that the fair foothold of national proposition and provincial proposition is not in the proposition system itself, but should have something else to say.

\subsection{Ensuring the Fairness of Basic Education Is a Topic that Can not Be Bypassed in this Game}

Both national proposition and provincial proposition have great practical significance in promoting the fairness of the college entrance examination itself, but the starting point and end point of the policy goal of the college entrance examination proposition is not only the college entrance examination system itself. Before the difference in the allocation of enrollment quotas has not been eliminated, there is basically no fairness in the whole system of college entrance examination, no matter the national or provincial propositions. Whatever the examination questions, no matter how well they are tested, the admission of colleges and universities is based on the total number of enrollment indicators obtained by the provinces, from high to low. Therefore, in the process of promoting the reform of college entrance examination proposition, the government and universities pay more attention to the issue of fair practice, how to use more scientific and standardized procedures and models to select high-quality talents, that is, procedural justice. Even if the national unified proposition, marking work is still organized by the provinces, the provincial marking teachers'grasp of the scoring standards is always different, so it is impossible to fundamentally eliminate the regional differences. On this premise, the national proposition and provincial proposition, for the enrollment of universities and the development of higher education in all provinces, hardly exist the problem of fairness. Universities in all provinces are positioned to enroll students according to their own level in proportion. Whether national proposition or provincial proposition, the ownership of proposition can not fundamentally affect the whole equality of Higher Education.

As an examination mechanism, the college entrance examination is a test of the level and ability of the whole elementary education stage. As an examination mechanism, the college entrance examination is a test of the level and ability of the whole elementary education stage. The college entrance examination proposition is the core factor of the college entrance examination known as the baton of basic education. The country has a vast territory, great differences in natural environment, different levels and modes of economic development, and different investment in education in different regions, as well as different educational development concepts and facilities formed by different regions. Therefore, the level and scale of basic education are different, so different college entrance examination proposition system has a huge 
impact on basic education. In the disputes between national propositions and provincial propositions, substantially, both sides are in favor of basic education and new curriculum reform. Supporters of the national unification proposition believe that the national proposition uses different versions of the national volume, which not only takes into account the differences between local basic education development and the new curriculum reform, but also monitors the national basic education level at a relatively unified level and narrows the regional gap in basic education. At the same time, it also encourages the state's inclination towards basic education policies in vulnerable areas and local governments'investment in basic education. And the provincial proposition is also conducive to the development of basic education."Sub provincial proposition... It is to further promote the reform of basic education and further promote quality education. The national syllabus is consistent and the basic standards are consistent. As for the examination questions, central government also have an organization to study and discuss each other, and the basic policy is also consistent. Central government have given more initiatives to the provinces. It turns out that the topic is good now. This work will only be conducive to basic education, higher education, so that more children have a more equitable opportunity to enter higher education, and accept quality education in a better way"[23].
The provincial proposition is based on the gap between provincial and provincial basic education, which accords with the development status of provincial and municipal economy and basic education. Therefore, in the game between national proposition and provincial proposition, the fairness of basic education has become an unavoidable topic in this game (see Figure 1 for details). The present situation of basic education influences the evolution of college entrance examination proposition system, and the reform of college entrance examination proposition system in turn profoundly affects the development of basic education, especially basic education curriculum. Therefore, the national proposition and the provincial proposition are related to the fairness of basic education and the balanced development of basic education. Balanced development of basic education is the basis of equity in basic education. The proposition of College Entrance Examination directly affects the allocation, development and cultivation of basic education resources (especially curriculum resources), further affects the development potential of regional basic education, and ultimately affects the equity of basic education. As Fan Xianzuo, a professor at the School of Education of Central China Normal University, said in an interview with Guangming Daily: College Entrance Examination has always been a standard, directly affecting high school teaching and even the whole basic education [24].

Decentralization, risk sharing mechanism

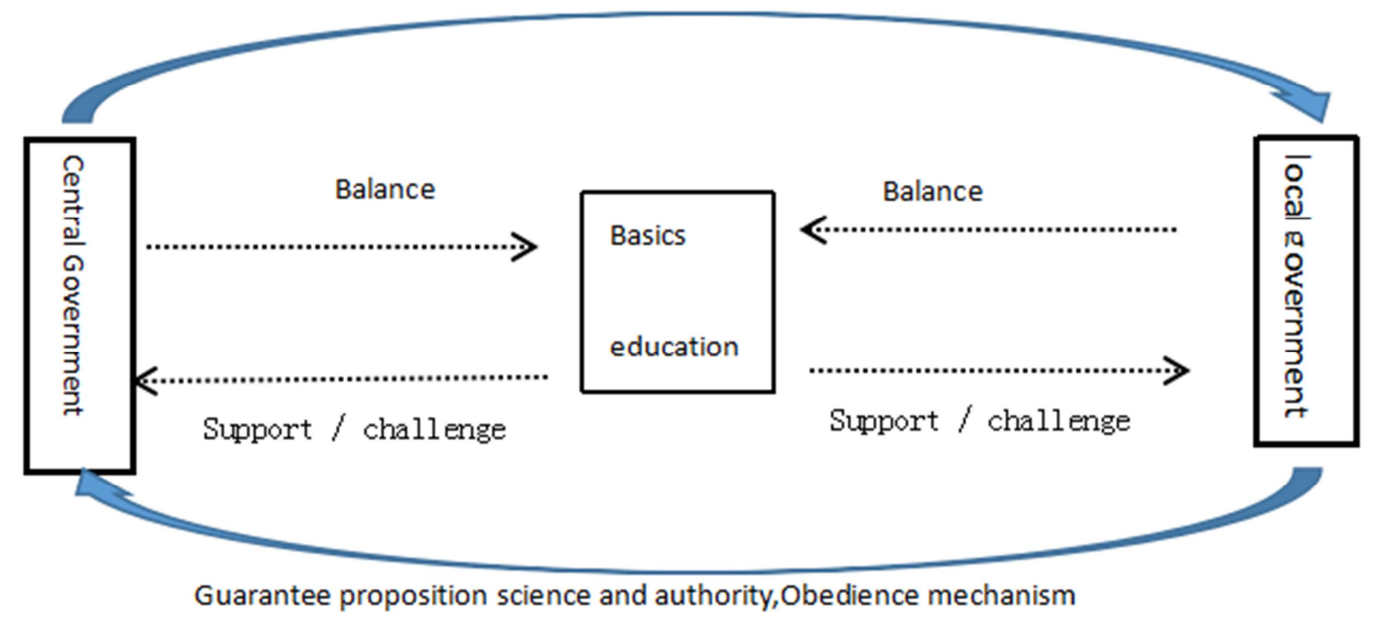

Figure 1. Game between national proposition and sub provincial proposition.

\section{Remaining Theory: Re-examining the Proposition of the College Entrance Examination and Returning to the Fair Question in the National Volume Era}

As long as it is a competitive mechanism, there will inevitably be a game, reflecting the conflict and balance of interests. The key to the problem is how to formulate filtering standards, whether they are reasonable, and whether they can maximize fairness. The proposition of college entrance examination is not only a purely technical problem, but also a major problem deeply affected by the development of national social economy and education reform. It is a systematic project which involves many factors such as economic development level, national political system, education system and so on [25]. The reform of college entrance examination proposition management system, which faces basic education directly in the college entrance examination system, is not a simple change in the organizational form of proposition. In order to achieve educational equity, it is impossible to reform the examination enrollment system only by changing the way of proposition on one test paper. Each conversion of national proposition and provincial proposition not only has a comprehensive consideration of the current situation of basic education, but also has a profound and 
comprehensive impact on basic education: Basic education values, curriculum outlook, school curriculum resources supply, teaching methods, school management structure, the relationship between high school education and University education, student evaluation methods, school development model, teachers'professional roles, school education support system, etc. [26], all of these are facing great changes. In the alternation of national propositions and provincial propositions, they learn from each other and gradually show the trend of integration and complementarity. This integration of national propositions and provincial propositions is a way to make up for the shortcomings of the propositions management system of college entrance examination. It is an effective reform measure to ensure the authoritativeness of propositions of college entrance examination and reduce the risk of propositions of college entrance examination. Since 2003, China began to carry out provincial propositions on a large scale. After more than ten years of development, provinces have formed relatively mature propositional teams, systems and operational mechanisms, and have made some new and beneficial explorations on the form and content of propositions. But it did not change the basic structure of the college entrance examination management system. Even provincial propositions are organized within the framework of the national unified examination. According to the National Unified Examination Syllabus for Admission to Universities and Colleges [27], provincial propositions are still managed by the Ministry of Education as a whole. The Examination Center of the Ministry of Education is responsible for guiding, training, supervising and evaluating the work of college entrance examination proposals of autonomous provinces, municipalities directly under the Central Government, autonomous regions and autonomous regions. Since 2014, China has gradually returned to the national proposition and expanded the national proposition radiation provinces year by year, which implies a further consideration of the issue of fairness."People's quest for the scientificity and impartiality of test propositions does not mean that people's views on the impartiality of test propositions have been unanimous. The definition and interpretation of the impartiality of test propositions vary with the social and political environment. People's unremitting pursuit of propositional fairness always chooses between the dilemma of functional defects and structural contradictions of fairness. This is all to seek a moderate balance between the scientific and impartiality of the examination from the value orientation and the technical level" [28]. Fairness as an action criterion and value orientation is the inherent regulation and fundamental motive force of social development [29]. As one of the most important social public resources, the fairness of education distribution is not only related to the fairness of social members'starting point and basic rights, but also to the widening or narrowing of the gap between social strata. College Entrance Examination Proposition Management System is the key link for the College Entrance Examination to play its resource allocation-oriented role, and it is the most effective way and means to ensure the fair and reasonable distribution of resources so far [30]. Therefore, it is necessary to reexamine the fairness when the proposition of the National College Entrance Examination returns to the era of the national paper: can the national proposition achieve real fairness? What kind of fairness is quality fairness?

Fairness and quality are the overall guiding principles of national education policy [31]. From the point of view of the national and provincial propositions currently implemented, the national propositions have unified standards, paying attention to the investigation of the main knowledge and students'basic abilities in basic education teaching, and so on. To a certain extent, these propositions can solve the problems of provincial and municipal examination papers with different difficulties and poor stability brought about by provincial and municipal propositions. The national proposition has become an effective ruler to monitor the basic education level and quality of provinces, municipalities directly under the Central Government and autonomous regions. From the perspective of economic benefits, the national proposition has reduced the total cost of college entrance examination proposition to a certain extent. From this perspective, returning to the national proposition has achieved the unification of fairness and efficiency. However, from the perspective of educational management system, whether this unified model can achieve quality equity remains to be further discussed. At the national level, the decision-making power of college entrance examination proposition is to try out provincial proposition, which is to balance the advantages and disadvantages of the country and effectively take care of the differences between local economy and education. While the state decentralizes part of the proposition power, local governments effectively share the risk that the proposition power is only in the hands of the central government. The weight of the proposition returns to the central government, and the emphasis on the unified proposition indicates that the decision-making process is still a major decision made by the state after considering the social public opinion and the development of the national economy, politics and basic education. But different from the decision-making system of the college entrance examination, the basic education of the country is divided into provinces and municipalities, while the overall right of basic education is in each province and municipality. Each province and municipality is directly responsible for the development and implementation of basic education teaching in the province and municipality. In this process, the ability and level of candidates brought about by regional differences and educational differences are different. Differences can not be eliminated. The consensus reached by scholars on the connotation of educational equity includes at least three aspects: equal right to education and equal opportunity to education; all children enjoy the right to education and receive education of roughly the same quality; and education suitable for personality differences [32]. That is to say, examination should emphasize unity (basic standard) and emphasize diversity (diversity and selectivity) [33]. This is the quality of education equity, but also the basic realization of the nine-year plan, China should pay more attention to promoting education 
equity. Quality equity is the higher and more essential goal of educational equity, and it is the essence of educational equity [34]. Although the national volume has different versions for different provinces and cities, it still fails to reflect the particularity of basic education teaching in each province and city. In recent years, the controversy over the regional tendentiousness of college entrance examination composition has been proof. According to the regulations of the State Council on the implementation of deepening the reform of examination and enrollment system: "In 2014, the central government launched a pilot reform of the examination and enrollment system. In 2017, we will comprehensively promote it. By 2020, we will basically establish a modern education and examination enrollment system with Chinese characteristics, form a test and enrollment model of classified examination, comprehensive evaluation and multiple enrollment, improve the institutional mechanism to promote fairness, scientific talent selection and supervision, and build a cohesive and communication system at all levels. All kinds of education, recognition of a variety of learning outcomes lifelong learning 'flyover', [35].

Therefore, the goal of the reform of college entrance examination is to establish the system of college entrance examination, which mainly focuses on the unified examination, ability test, multiple evaluation and classified enrollment [36]. "The college entrance examination must be reformed, but the reform must be rational and sound. If divorced from reality, it can only be a romantic reason for self talk"[37]. The reform of College Entrance Examination is a systematic project involving multiple interests and complex scope. Every measure in the reform of College Entrance Examination may have a profound impact on fairness. The result of the reform may be to promote fairness, to hinder the realization of fairness, or to fall into the trap of fairness [38]. Returning to the national proposition, implementation of the Principle of Equality before Scoring, effectively compensating for the "reverse discrimination" in the equality of educational opportunities. But at present, the enrollment system still retains regional differences in the reality of large-scale implementation of the national roll, whether to achieve real equity, especially for the western region where basic education is not mature enough, this practice has a kind of divorce from reality "too hasty" suspicion. Therefore, through the reform of the management system of college entrance examination proposition, the Fairness of Examination which is not considered by a test paper is Realized. How to loosen the binding on the word "unification" [39] is the key to the reform of college entrance examination proposition system. In this process, the government should fully consider the main social contradictions and the actual situation of the country, devote itself to strengthening the professional construction of local examination institutions, and improve the level and ability of local examination institutions. The proposition should conform to the actual development of local basic education and at the same time improve the level of local basic education. Only in this way, fairness in college entrance examination can be truly realized.

\section{Conclusion}

As the article draws to a close, several points need to be emphasized again:

(1) In the whole research, we can see that the national proposition and the provincial proposition have their own advantages and disadvantages, and "fairness" provides a "legitimacy" coat for each alternation of the national proposition and the provincial proposition. Therefore, rather than using "fairness" to describe the game between national proposition and provincial proposition, it is more appropriate to use "who is more reasonable" to describe it.

(2) So far, there is no "who is more reasonable" standard that both sides of the game believe. The social relevance of college entrance examination in China is too high, so on the one hand, almost every year there is a "wind" about the reform of college entrance examination or the emergence of measures, but on the other hand, these reforms are very cautious. Especially the reform of proposition management system is not only the change of proposition ownership, but also the stability of the whole society.

(3) In this case, because there is no standard that both sides are convinced of, is it better not to reform than reform, that is, to stick to a certain proposition form all the time, but to have less controversy? At present, it is impossible to know the ideas of the candidates and parents directly related to the college entrance examination, but the researchers believe that it is a good thing for basic education. After all, for the whole stage of basic education in China, the college entrance examination is the most intuitive testing tool for its quality. Therefore, once the form of college entrance examination proposition is fixed, the goal of basic education, teaching process and so on are more clear.

(4) Of course, this is just the idea of researchers. After all, in China, the college entrance examination plays a baton role. The reform of college entrance examination effectively promotes the reform of basic education. Although the reform of basic education has many goals, there is no doubt that the college entrance examination plays an important and even major role in it. Therefore, it should be assumed that if the college entrance examination has not been reformed, then the reform of basic education can remain vigorous.

(5) It should be emphasized that although it is impossible to find a unified criterion to judge the national proposition and the provincial proposition "who is more reasonable", researchers believe that this can not be an excuse for not reforming. After all, the times are changing and knowledge is renewing. Perhaps through gradual attempts, a proposition form that can make all parties relatively satisfied will eventually appear, which is worth looking forward to. 


\section{References}

[1] Huang Guang Yang. Several issues of primary concern in the reform of college entrance examination: [J]. Curriculum, Textbook, Teaching method, 2011(6): 9.

[2] Liu Haifeng. Retrospect and Prospect of college entrance examination reform [J]. Education Research, 2007 (11): 19.

[3] Huang Xiaomei. Rational Examination of the Reform of College Enrollment Examination System: Evaluation of the Series of Research on College Entrance Examination Reform [J]. University Publication, 2008 (5): 70.

[4] Liu Haifeng. Fairness in college entrance examination or efficiency priority [J]. Higher Education Research, 2011 (5): 4.

[5] Wang Houxiong. Practical Dilemma and dilemma in the fairness of college entrance examination proposition [J]. education research, 2008 (8): 24.

[6] Yang Xue Wei. History of Chinese examinations [M]. Beijing: Higher Education Press, 2003: 3.

[7] Liu Wanyong. The Ministry of Education will make every effort to guarantee the implementation of the provincial proposition of the National College Entrance Examination [EB/OL]. China Education and Scientific Research Computer Network. Basic Education. Basic Education News. (2004-03-25) [2017-10-01]. http://www.edu.cn/ji_jiao_news_279/20060323/t20060323_9096 8.shtml.

[8] Liu Haifeng, Gu Zhenyu. Small Incident Initiated Great Reform: Origin and Trend of Provincial Proposition in College Entrance Examination [J]. Journal of Hebei Normal University (Educational Science Edition), 2012 (5): 17.

[9] State Council. State Council's Opinions on Deepening the Reform of Examination Enrollment System [EB/OL]. Chinese Government Network. Government Information Opening. (2014-09-04) [2017-10-01] http://www.gov.cn/zhengce/content/2014-09/04/content_9065. htm.

[10] Li Muzhou. From "Alternation" to "Hybridity": Historical Choice of the Way of Proposition and Score in College Entrance Examination [J]. Examination Research, 2011 (5): 23-24.

[11] Liao Pingsheng. Examination is a science [M]. Wuhan: Huazhong Normal University press, 2003: 109.

[12] Zhang Sheng. Ethical Examination and Empirical Research on Equity in College Entrance Examination [D]. Ph.D. Dissertation. Changsha: School of Public Administration, Central South University, 2013: 64.

[13] Zhou Bin. On the lack of educational function of the college entrance examination system and promotion of [J]. Education Theory and Practice, 2009 (1): 17.

[14] Zheng Ruoling. Anxiety and exploration of fairness in college entrance examination $[\mathrm{J}]$. Peking University education review, 2010 (2): 26.

[15] Chen Tan, Hu Xiao Rawls Principle and Institutional Logic of Higher Education Equity [J]. Modern University Education, 2008 (4): 4.

[16] $\mathrm{Hu}$ Maoliang, a provincial proposition, is one of the most important leaders in the [N]. China Education Daily,
2005-11-09 (009).

[17] Anonymous, Editor. Reviewing the Provincial Proposition of College Entrance Examination Reform: Provincial Proposition, Achieving Leap-forward Development in College Entrance Examination Reform (Part I) [N]. China Education Daily, 2006-09-27 (006).

[18] Wang Yunfang proposed to restore the national college entrance examination unified proposition [N]. China Education Daily, 2013-06-17 (007).

[19] Easton, D. Political System - A Study of Political Science [M]. Ma Qinghuai, Translated. Beijing: Business Press, 1993: 123.

[20] Rawls, J. theory of justice [M]. He Huaihong, et al. Beijing: China Social Sciences Press, 1988: 101.

[21] Li Lifeng. Multidimensional examination and Reflection on the reform of the independent proposition of the college entrance examination. [J]. examination research, 2011 (2): 9.

[22] Anonymous, Editor. Reviewing the Provincial Proposition of College Entrance Examination Reform: Provincial Proposition, Achieving Leap-forward Development in College Entrance Examination Reform (Part II) [N]. China Education Daily, 2006-09-27 (006).

[23] Zhou Ji, Minister of Education: Provincial proposition of college entrance examination has advantages and disadvantages [EB/OL]. Official website of China Youth Daily. Zhongqing Online.

[24] Chen Peng. The college entrance examination topic is back to the era of "national volume" [N]. Guangming Daily, 2015-04-03 (006).

[25] Yu Yang. Research on the advantages of national unity in the national college entrance examination $[\mathrm{J}]$. Hubei entrance examination, 2015 (6): 25.

[26] Duan Liufang. Zhang Zhiyong: The profound impact of the new round of college entrance examination reform on basic education $[\mathrm{EB} / \mathrm{OL}]$. China Networks. Education China. Industry dynamics. (2015-11-10)[2017-10-01]. http://edu.china.com.cn/2015-11/10/content_37027814.htm.

[27] Ministry of education. Interim Measures for the assignment of the national unified examination for colleges and Universities: [EB/OL]. Ministry of education official website. Information disclosure.(2006-04-19)[2017-10-01]. http://old.moe.gov.cn//publicfiles/business/htmlfiles/moe/moe _1304/200701/18439.html.

[28] Wang Houxiong. Practical Dilemma and dilemma of fairness in college entrance examination proposition [J]. education research, 2008 (8): 25-26.

[29] Jing Tian Kui. As a just development of [J]. social science front, 2003 (6): 216.

[30] Jiang Chang. On the connotation and essence of the justice of education examination [J]. Hubei entrance examination, 2007 (10): 6 .

[31] Office of National Working Group on Medium and Long Term Education Reform and Development Program. National Medium and Long Term Education Reform and Development Program (2010-2020) [EB/OL]. Official website of Ministry of Education. Information disclosure. (2010-07-29)[2017-10-01]. http://www.moe.edu.cn/srcsite/A01/s7048/201007/t20100729 _171904.html. 
[32] Cheng Hongyan. Debate on the relationship between educational equity and educational quality $[\mathrm{J}]$. Nanjing Social Sciences, 2014 (11): 116.

[33] Tan Song Hua, Wang Jian. Pursue quality education equality [J] People's Education, 2011 (18): 2-3.

[34] Wu Gangping. Equality of Opportunity and Quality in Compulsory Education in China [J]. Journal of Hebei Normal University (Educational Science Edition), 2000 (1): 40.

[35] Opinions of the State Council on implementing the reform of the examination and enrollment system of the State Council [EB/OL]. Government Information Disclosure.(2014-09-04)[2017-10-01]. http://www.gov.cn/zhengce/content/2014-09/04/content 9065. htm.
[36] Liu Haifeng. Ideas, principles and policy proposals for the reform of college entrance examination [J]. education research, 2009 (7): 3

[37] Hu Zhengyu, Mao Jianping. Difficulties and Prospects for the Reform of the Dual-track College Entrance Examination [J]. Research on Educational Development, 2014 (10): 14.

[38] Yu Cheng, Queen Xiong. Fair risk analysis of college entrance examination reform $[\mathrm{J}]$. Course, Textbook, Teaching method, 2015 (9): 84.

[39] Zeng Zhaoxin. The college entrance examination should untie [J]. modern university education on the "Tong" word, 2006 (3): 25 . 